\title{
Leaf Shape, Growth, and Antioxidant Phenolic Compounds of Two Lettuce Cultivars Grown under Various Combinations of Blue and Red Light-emitting Diodes
}

\author{
Ki-Ho Son and Myung-Min $\mathrm{Oh}^{\mathbf{1}}$ \\ Department of Horticultural Science, Chungbuk National University, 52 \\ Naesudong-ro, Heungduk-gu, Cheongju 361-763, South Korea
}

Additional index words. Lactuca sativa, light quality, LED, phytochemicals, photomorphogenesis, plant factory

\begin{abstract}
Light-emitting diodes (LEDs) of short wavelength ranges are being developed as light sources in closed-type plant production systems. Among the various wavelengths, red and blue lights are known to be effective for enhancing plant photosynthesis. In this study, we determined the effects of blue and red LED ratios on leaf shape, plant growth, and the accumulation of antioxidant phenolic compounds of a red leaf lettuce (Lactuca sativa L. 'Sunmang') and a green leaf lettuce (Lactuca sativa L. 'Grand Rapid TBR'). Lettuce seedlings grown under normal growth conditions $\left(20^{\circ} \mathrm{C}\right.$, fluorescent lamp + highpressure sodium lamp $177 \pm 5 \mu \mathrm{mol} \cdot \mathrm{m}^{-2} \cdot \mathrm{s}^{-1}$, 12-hour photoperiod) for 18 days were transferred into growth chambers that were set at $20{ }^{\circ} \mathrm{C}$ and equipped with various combinations of blue $(456 \mathrm{~nm})$ and red $(655 \mathrm{~nm})$ LEDs [blue:red = 0:100 (0 B), 13:87 (13 B), 26:74 (26 B), 35:65 (35 B), 47:53 (47 B) or 59:41 (59 B)] under the same light intensity and photoperiod $\left(171 \pm 7 \mu \mathrm{mol} \cdot \mathrm{m}^{-2} \cdot \mathrm{s}^{-1}, 12\right.$-hour photoperiod). Leaf width, leaf length, leaf area, fresh and dry weights of shoots and roots, chlorophyll content (SPAD value), total phenolic concentration, total flavonoid concentration, and antioxidant capacity were measured at 2 and 4 weeks after the onset of LED treatment. The leaf shape indices (leaf length/leaf width) of the two lettuce cultivars subjected to blue LEDs treatment were similar to the control, regardless of the blue-to-red ratio during the entire growth stage. However, 0 B (100\% red LED) induced a significantly higher leaf shape index, which represents elongated leaf shape, compared with the other treatments. Increasing blue LED levels negatively affected lettuce growth. Most growth characteristics (such as the fresh and dry weights of shoots and leaf area) were highest under 0 B for both cultivars compared with all other LED treatments. For red and green leaf lettuce cultivar plants, shoot fresh weight under $0 \mathrm{~B}$ was 4.3 and 4.1 times higher compared with that under $59 \mathrm{~B}$ after 4 weeks of LED treatment, respectively. In contrast, the accumulation of chlorophyll, phenolics (including flavonoids), and antioxidants in both red and green leaf lettuce showed an opposite trend compared with that observed for growth. The SPAD value (chlorophyll content), total phenolic concentration, total flavonoid concentration, and antioxidant capacity of lettuces grown under high ratios of blue LED (such as $59 \mathrm{~B}, 47 \mathrm{~B}$, and $35 \mathrm{~B}$ ) were significantly higher compared with $0 \mathrm{~B}$ or control conditions. Thus, this study indicates that the ratio of blue to red LEDs is important for the morphology, growth, and phenolic compounds with antioxidant properties in the two lettuce cultivars tested.
\end{abstract}

The consumption of plant-based foods represents one of the essential components for the nutrition of humans. In this aspect, increasing crop yield is the most fundamental and important issue for farmers and agronomists and will continue to be in the future. The importance of the fruits and vegetables that we ingest daily has been rediscovered, because horticultural crops contain various types of health-promoting phytochemicals,

Received for publication 18 Mar. 2013. Accepted for publication 11 June 2013.

${ }^{1}$ To whom reprint requests should be addressed; e-mailmoh@cbnu.ac.kr. factor. Basically, light is an energy source for photosynthesis. In addition, various components contribute to light serving as a signal stimulus to plants, including light intensity, light quality, and daylength. Plants perceive light signals through photoreceptors such as phytochromes, cryptochromes, and phototropins. Consequently, most developmental processes that occur throughout the life cycle of plants are dependent on light, including seed germination, phototropism, gravitropism, chloroplast movement, shade avoidance, circadian rhythms, and flower induction (Carvalho et al., 2011; Jiao et al., 2007). In the case of growing a crop under different light sources, each cultural practice must be differentiated, because each light source has a unique light quality that directly affects plant growth and development.

Recently, LEDs have been used as sources of artificial lighting in closed-type plant production systems, where environmental conditions are controlled, allowing crops to be produced throughout the year regardless of external weather conditions. In comparison with other conventional artificial lighting sources used in plant cultivation, LEDs have the advantages of high light-conversion efficiency with low radiant heat output, semipermanence, and small mass; hence, plants may be irradiated close to the plants. In addition, LEDs are available in a variety of narrow wavebands; hence, it is possible to optimize light quality to improve both crop yield and quality (Morrow, 2008; Yeh and Chung, 2009).

Blue and red LEDs are usually used for plant growth because chlorophyll a and b efficiently absorb wavelengths in the blue (maximum absorption at 430 and $453 \mathrm{~nm}$ ) and red (maximum absorption at 663 and 642 $\mathrm{nm}$ ) ranges (Hopkins and Huner, 2004). Previous studies assessing the effects of red and blue wavelengths on plants indicated that red LED generally induces plant growth by increasing fresh and dry plant weight, plant height, and leaf area (Heo et al., 2012; Johkan et al., 2010; Wang et al., 2009; Wu et al., 2007). In comparison, blue LED influences photosynthetic function, chlorophyll formation, and chloroplast development rather than having a direct effect on biomass accumulation (Johkan et al., 2010; Savvides et al., 2012; Wang et al., 2009). The synergetic effect was observed when mixtures of blue and red LEDs were used to irradiate plants. Mixed light conditions enhance the growth of various vegetables, including lettuce, more compared with red LEDs alone (Hogewoning et al., 2010; Matsuda et al., 2007; Savvides et al., 2012; Stutte et al., 2009; Yorio et al., 2001). However, other studies have reported the opposite results (Heo et al., 2012; Johkan et al., 2010). It is difficult to understand how plants respond to changes in blue and red light ratios because most existing LED-related studies simply compare plant growth for specific ratios of blue and red LEDs, leading to inconsistent results

Thus, this study aimed at determining the effect of different blue and red LED ratios on 
the morphological changes, growth characteristics, and the accumulation of antioxidant phenolic compounds of two lettuce cultivars. The results obtained from this study are expected to provide baseline information toward designing artificial lighting sources in closed-type plant production systems.

\section{Materials and Methods}

Plant growth conditions and light spectrum. Seeds of red leaf lettuce (Lactuca sativa L. 'Sunmang'; Nongwoo Bio Co., Suwon, Korea) and green leaf lettuce (Lactuca sativa L. 'Grand Rapid TBR'; Asia Seed Co., Seoul, Korea) were sown in a 105-plug tray (32 $\mathrm{mL} /$ cell, two seeds per cell) containing a growing medium (Myung-Moon; Dongbu Hannong Co., Seoul, Korea). One of two seedlings per cell was thinned 1 week after sowing. The plants were then grown within a growth chamber (DS-96S; Dasol Scientific Co., Hwaseong, Korea) with normal growing conditions $\left[20{ }^{\circ} \mathrm{C}\right.$, fluorescent lamp + high-pressure sodium lamp, photosynthetic photon flux $(P P F) 177 \pm 5$ $\mu \mathrm{mol} \cdot \mathrm{m}^{-2} \cdot \mathrm{s}^{-1}, 12-\mathrm{h}$ photoperiod] for $18 \mathrm{~d}$. Fifteen seedling plugs per treatment were transferred to a growth chamber (VS-1203P1; Vision Scientific Co., Daejeon, Korea) equipped with six different blue and red LED ratios and a growth chamber (DS-96S; Dasol Scientific Co., Hwaseong, Korea) to serve as the control. The six lighting sources using LEDs, which were plate type $(48 \times 48 \mathrm{~cm}$, length $\times$ width), were manufactured to generate a combination of blue $(456 \mathrm{~nm}$; Itswell Co., Incheon, Korea) and red (655 nm; Bright LED Electronics Co., Seoul, Korea) LEDs. The spectral distribution was initially measured at $25 \mathrm{~cm}$ from LED lighting sources to top of the pots and at five points (center and four edges of a tray including pots) using a spectroradiometer (LI-1800; LI-COR, Lincoln, NE), which presented as relative spectral distribution (Fig. 1). All plants were grown at $20^{\circ} \mathrm{C}, P P F$ of $171 \pm$ $7 \mu \mathrm{mol} \cdot \mathrm{m}^{-2} \cdot \mathrm{s}^{-1}$, and a $12-\mathrm{h}$ photoperiod for 4 weeks. The $P P F$ of each LED treatment, which was measured at the top of lettuce plants, was maintained at a similar level by adjusting currents of LED lighting systems. To minimize light distribution being disproportionate within each treatment, the pots were systematically rearranged everyday. For the first $18 \mathrm{~d}$ after sowing, distilled water $(2 \mathrm{~L})$ was subirrigated to pots in a tray at intervals of 2 to $3 \mathrm{~d}$, and a nutrient solution for lettuce $(17.3 \mathrm{~N}-4.0 \mathrm{P}-8.0 \mathrm{~K})$ was subirrigated to the lettuce plants once a week for the rest of the cultivation period. The $\mathrm{pH}$ and electrical conductivity of the nutrient solution were 5.5 and $1.16 \mathrm{dS} \cdot \mathrm{m}^{-1}$, respectively.

Growth characteristics. Growth characteristics such as the fresh and dry weights of shoots and roots, shoot/root ratio ( $\mathrm{S} / \mathrm{R}$ ratio), total leaf area, and chlorophyll content (SPAD value) were measured at 4 weeks after the onset of LED treatment. The shoots and roots were dried at $70{ }^{\circ} \mathrm{C}$ in a drying oven
(FS-420; Advantec Co., Tokyo, Japan) for $3 \mathrm{~d}$ and were weighed to determine dry weight using a scale (Si-234; Denver Instrument, New York, NY). The S/R ratio was calculated from the fresh weight of shoots and roots. Total leaf area and SPAD value were measured using a leaf area meter (LI-3000A; LI-COR) and a portable chlorophyll meter (SPAD-502; Minolta, Osaka, Japan), respectively. The most fully expanded leaf was used for leaf shape indices, which were determined as the leaf length divided by the leaf width at 0,2 , and 4 weeks after the onset of LED treatment.

Chlorophyll fluorescence. Chlorophyll fluorescence [maximum variable fluorescence $(\mathrm{Fv})$ /maximum fluorescence (Fm)] was measured to evaluate the maximal photochemical efficiency of photosystem II in 'Grand Rapid TBR' green leaf lettuce plants grown under various combinations of blue and red LEDs and under the control treatment. Measurements of $\mathrm{Fv} / \mathrm{Fm}$ were recorded at 0,2 , and 4 weeks after the onset of LED treatment using a chlorophyll fluorescence meter (PAM 2000; Walz, Effeltrich, Germany). Fully expanded leaves were kept in the dark for $\approx 30 \mathrm{~min}$, and then $\mathrm{Fm}$ and minimum fluorescence (Fo) were obtained by applying $1100 \mu \mathrm{mol} \cdot \mathrm{m}^{-2} \cdot \mathrm{s}^{-1} \mathrm{PPF}$ saturating light pulse $(20 \mathrm{kHz})$. The maximum PS II quantum yield $(\mathrm{Fv} / \mathrm{Fm})$ was calculated using the equation $\mathrm{Fv} / \mathrm{Fm}=(\mathrm{Fm}-\mathrm{Fo}) / \mathrm{Fm}$.

Total phenolic concentration. To analyze the total phenolic concentration of leaves, the

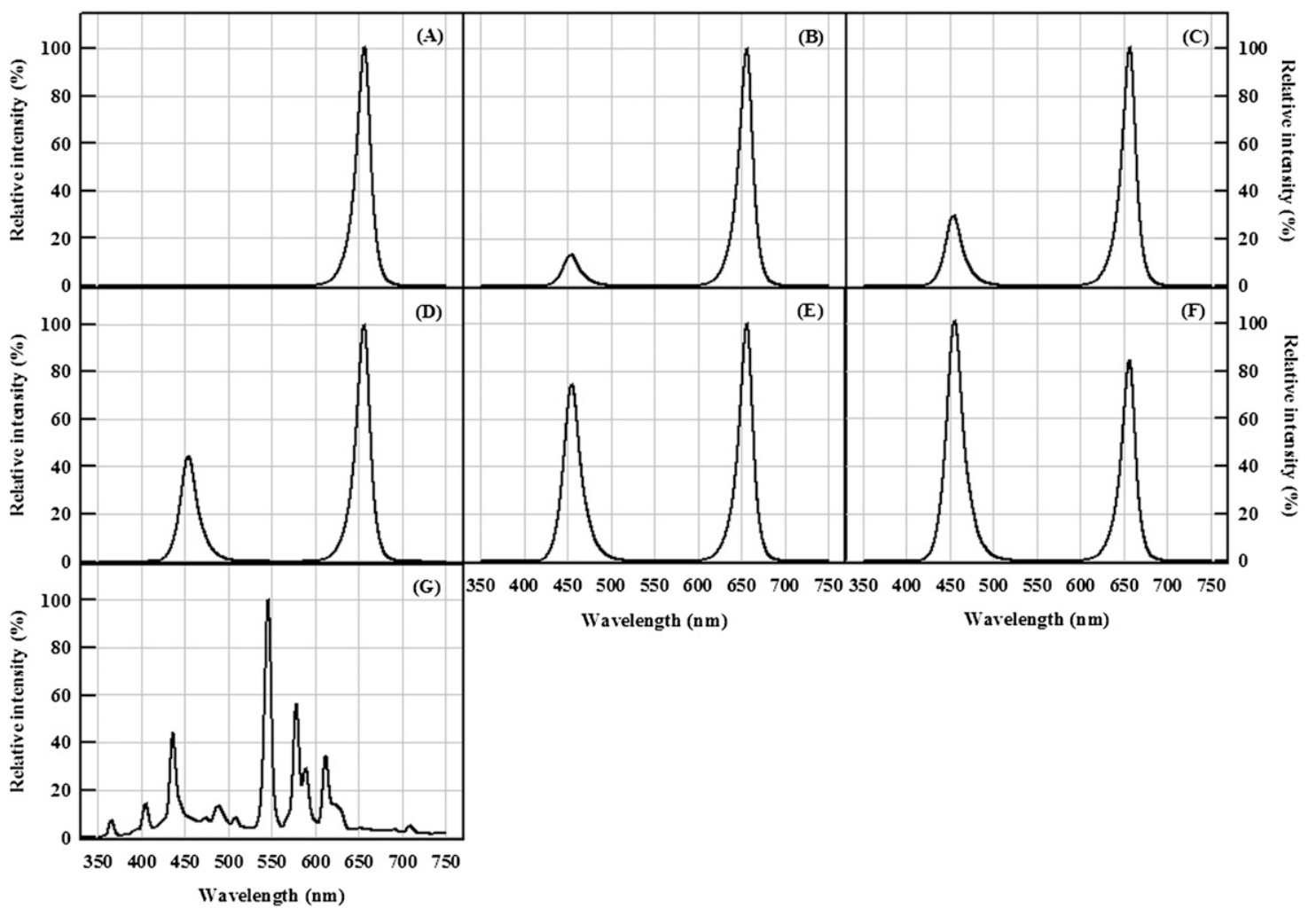

Fig. 1. Relative spectral distribution of various combinations of blue and red light-emitting diodes (LEDs) used in this study. $(\mathbf{A})$ blue:red $=0: 100,(\mathbf{B})$ blue:red $=$ 13:87, (C) blue:red = 26:74, (D) blue:red = 35:65, (E) blue:red = 47:53, (F) blue:red = 59:41, and (G) control (fluorescent lamp + high-pressure sodium lamp). Total photosynthetic photon flux $(P P F)$ was $171 \pm 7 \mu \mathrm{mol} \cdot \mathrm{m}^{-2} \cdot \mathrm{s}^{-1}$ in each treatment. Spectral scans were measured at $25 \mathrm{~cm}$ from LED lighting sources and at five points (a center and four edges of each tray of pots). 
third leaf from the top was collected at 4 weeks after the onset of LED treatment and stored in a deep freezer at $-70{ }^{\circ} \mathrm{C}$ (DF8524; IlShinBioBase Co., Dongducheon, Korea) until use. The total phenolic concentration of lettuce was determined using the modified Folin-Ciocalteu reagent method (Ainsworth and Gillespie, 2007). Approximately $0.2 \mathrm{~g}$ of each sample was macerated in a mortar and pestle with liquid nitrogen and extracted with $3 \mathrm{~mL}$ of $80 \%(\mathrm{v} / \mathrm{v})$ acetone for a phenolic substance. Approximately $1 \mathrm{~mL}$ of extract was placed in a microtube and incubated in darkness at $4{ }^{\circ} \mathrm{C}$ overnight. Subsequently, the extract was centrifuged at $905 g_{\mathrm{n}}$ for $2 \mathrm{~min}$, and the supernatant was used to measure the total phenolic concentration. A mixture of $135 \mu \mathrm{L}$ distilled water, $750 \mu \mathrm{L} 1 / 10$ dilution Folin-Ciocalteau reagent (Sigma-Aldrich, St. Louis, MO), and $600 \mu \mathrm{L} 7.5 \%$ (w/v) $\mathrm{Na}_{2} \mathrm{CO}_{3}$ was added to $50 \mu \mathrm{L}$ of the extract and vortexed for $10 \mathrm{~s}$. The mixture was incubated at $45^{\circ} \mathrm{C}$ in a water bath (MSB-2011D; Mono Tech Co., Siheung, Korea) for $15 \mathrm{~min}$ and allowed to cool down to room temperature. The absorbance of samples was read at $765 \mathrm{~nm}$ with a blank [50 $\mu \mathrm{L}$ of $80 \%(\mathrm{v} / \mathrm{v})$ acetone] using a spectrophotometer (ultraviolet-1800; Shimadzu Co., Kyoto, Japan). A standard curve was prepared from a freshly made 1 $\mathrm{mg} \cdot \mathrm{mL}^{-1}$ gallic acid [Acros Organics, Geel, Belgium in $80 \%(\mathrm{v} / \mathrm{v})$ acetone $)$ ] stock solution. The total phenolic concentration of lettuce was expressed as milligrams gallic acid equivalent (GAE) per gram of fresh weight of lettuce leaves.

Antioxidant capacity. The collection method for antioxidant capacity was the same as that for total phenolic concentration. The antioxidant capacity of lettuce leaves was determined using the modified 2,2' -azino-bis (3-ethylbenzthiazoline-6-sulfonic acid) (ABTS) method (Miller and RiceEvans, 1996; Pennycooke et al., 2005). Lettuce samples were extracted with $3 \mathrm{~mL}$ of $80 \%(\mathrm{v} / \mathrm{v})$ acetone, and the extract was incubated overnight in darkness at $-20{ }^{\circ} \mathrm{C}$. Subsequently, the extract was centrifuged at $905 g_{\mathrm{n}}$ for $2 \mathrm{~min}$, and the supernatant was used to measure the antioxidant capacity.
ABTS [(2.5 mm) Sigma-Aldrich] solution was mixed with $\approx 0.4 \mathrm{~g}$ of $\mathrm{MnO}_{2}$ (SigmaAldrich) to generate ABTS radical cation (ABTS*) for $30 \mathrm{~min}$ at room temperature. ABTS* solution was filtered using a $0.22-\mu \mathrm{M}$ syringe filter (NS25-N02; Noble Bio Co., Suwon, Korea) and was incubated in a water bath at $30^{\circ} \mathrm{C}$. To obtain an ABTS* solution with an absorbance of $0.7( \pm 0.02)$ at $730 \mathrm{~nm}$, $5 \mathrm{~mm}$ phosphate-buffered saline solution [pH 7.4, ionic strength (150 mM NaCl)] was used for dilution. A $100 \mu \mathrm{L}$ of the extract was added to $1 \mathrm{~mL}$ of ABTS* solution and vortexed for $10 \mathrm{~s}$ and then the mixture was measured at $730 \mathrm{~nm}$ in a spectrophotometer after $1 \mathrm{~min}$ of reaction period. Trolox [(6-hydroxy-2,5,7,8-tetramethylchroman-2carboxyl acid) (Sigma-Aldrich)] standard curve was prepared using the 0.5 -mm stock solution. The antioxidant capacity of lettuce was expressed as millimoles Trolox equivalent antioxidant capacity (TEAC) per gram of fresh weight of lettuce leaves.

Total flavonoid concentration. Total flavonoid concentration was determined according to the method of Dewanto et al. (2002). Approximately $0.2 \mathrm{~g}$ of the fourth leaf from the top, which were collected at 4 weeks after the onset of LED treatment, were extracted with $3 \mathrm{~mL}$ of $70 \%(\mathrm{v} / \mathrm{v})$ ethanol $(\mathrm{pH}$ 3.2 , using formic acid) and placed in the dark at $4{ }^{\circ} \mathrm{C}$ for $12 \mathrm{~h}$. Subsequently, the extract was centrifuged at $905 g_{n}$ for 2 min, and the supernatant was used to measure the total flavonoid concentration. A mixture of $1.25 \mathrm{~mL}$ distilled water and $75 \mu \mathrm{L}$ of $5 \%$ $\mathrm{NaNO}_{2}$ was added to $250 \mu \mathrm{L}$ of the extract. After 6 and $5 \mathrm{~min}$, the mixture was sequentially added to $150 \mu \mathrm{L}$ of $10 \% \mathrm{AlCl}_{3}$ and $500 \mu \mathrm{L}$ of $1 \mathrm{M} \mathrm{NaOH}$ with $275 \mu \mathrm{L}$ of distilled water, respectively. A blank (control) was prepared using $250 \mu \mathrm{L}$ of $70 \%$ ethanol $(\mathrm{pH}$ 3.2 , using formic acid) instead of the extract. The absorbance of the mixture was measured at $510 \mathrm{~nm}$. The total flavonoid concentration of lettuce was expressed as milligrams of $(+)$-catechin hydrate equivalents per gram of fresh weight of lettuce leaves.

Statistical analysis. Four plants per treatment were used to determine all growth and antioxidant phenolic compounds, except for leaf shape index and SPAD value, which has eight samples per treatment. Chlorophyll fluorescence was determined by using three plants per treatment. The experiment was repeated twice to verify reproducibility. The statistical analysis was performed using the statistical analysis system (SAS 9.2; SAS Institute Inc., Cary, NC) program. Analysis of variance was performed and Duncan's multiple range test was used to compare the means.

\section{Results}

Growth characteristics and leaf shape. Both lettuce cultivars grown under various ratios of blue to red LEDs showed significant differences in growth characteristics such as the fresh and dry weights of shoots and roots, leaf area, and $\mathrm{S} / \mathrm{R}$ ratio (Table 1). For the red leaf lettuce 'Sunmang', the fresh and dry weights of shoots and leaf area increased with an increasing proportion of red LEDs. The fresh weight of 0 B (100\% red LED) was $\approx 2.8$ times higher than that of control. In addition, $13 \mathrm{~B}$ and $26 \mathrm{~B}$ significantly induced a higher fresh weight of shoots compared with the control, although these treatments were less effective than $0 \mathrm{~B}$. In comparison, an increase in blue LED ratio had a negative effect on shoot growth. Treatments of $35 \mathrm{~B}$, $47 \mathrm{~B}$, and $59 \mathrm{~B}$ showed no significant difference in the fresh and dry weights of shoots and leaf area compared with the control. As the ratio of red LED increased, the lettuce also showed more vigorous root growth, which was a similar trend as that observed for shoot growth. The $\mathrm{S} / \mathrm{R}$ ratio was highest for lettuce plants grown under $0 \mathrm{~B}$, whereas blue LEDs induced a significant decrease in this ratio. Some of the results obtained for the green leaf lettuce 'Grand Rapid TBR' differed from those obtained for 'Sunmang', although overall trend was similar for both cultivars. For 'Grand Rapid TBR', the fresh weight of shoots was significantly higher under $0 \mathrm{~B}$ and $13 \mathrm{~B}$ compared with the control, whereas root growth was unaffected by blue and red LED ratios. 'Grand Rapid

Table 1. Growth characteristics of lettuce plants grown under various combinations of blue and red light-emitting diodes (LEDs) at 4 weeks after the onset of LED treatment $(\mathrm{n}=4)$.

\begin{tabular}{|c|c|c|c|c|c|c|c|}
\hline \multirow[b]{2}{*}{ Cultivar } & \multirow[b]{2}{*}{ Light source } & \multicolumn{2}{|c|}{ Fresh wt (g/plant) } & \multicolumn{2}{|c|}{ Dry wt (g/plant) } & \multirow[b]{2}{*}{ Leaf area $\left(\mathrm{cm}^{2}\right)$} & \multirow[b]{2}{*}{ Shoot/root ratio } \\
\hline & & Shoot & Root & Shoot & Root & & \\
\hline \multirow{4}{*}{ Sunmang (red leaf) } & $13 \mathrm{~B} / 87 \mathrm{R}$ & $29.86 \mathrm{~b}$ & $2.26 \mathrm{a}$ & $1.34 \mathrm{~b}$ & $0.11 \mathrm{ab}$ & $568.46 \mathrm{~b}$ & $13.30 \mathrm{bc}$ \\
\hline & $47 \mathrm{~B} / 53 \mathrm{R}$ & $14.21 \mathrm{c}$ & $1.38 \mathrm{bc}$ & $0.79 \mathrm{c}$ & $0.06 \mathrm{~d}$ & $325.62 \mathrm{c}$ & $10.39 \mathrm{~cd}$ \\
\hline & $59 \mathrm{~B} / 41 \mathrm{R}$ & $9.47 \mathrm{c}$ & $1.09 \mathrm{c}$ & $0.51 \mathrm{c}$ & $0.05 \mathrm{~d}$ & $228.44 \mathrm{c}$ & $8.90 \mathrm{~d}$ \\
\hline & Control $^{\mathrm{y}}$ & $14.60 \mathrm{c}$ & $1.51 \mathrm{bc}$ & $0.72 \mathrm{c}$ & $0.07 \mathrm{~cd}$ & $338.63 \mathrm{c}$ & $9.43 \mathrm{~d}$ \\
\hline \multirow{5}{*}{ Grand Rapid TBR (green leaf) } & $26 \mathrm{~B} / 74 \mathrm{R}$ & $18.33 \mathrm{de}$ & $1.23 \mathrm{~cd}$ & $0.99 \mathrm{bc}$ & $0.05 \mathrm{c}$ & $480.61 \mathrm{c}$ & $15.26 \mathrm{~b}$ \\
\hline & $35 \mathrm{~B} / 65 \mathrm{R}$ & $13.37 \mathrm{e}$ & $0.94 \mathrm{~d}$ & $0.75 \mathrm{c}$ & $0.05 \mathrm{c}$ & $354.06 \mathrm{c}$ & $14.36 \mathrm{~b}$ \\
\hline & $47 \mathrm{~B} / 53 \mathrm{R}$ & $26.81 \mathrm{c}$ & $2.00 \mathrm{~b}$ & $1.42 \mathrm{ab}$ & $0.09 \mathrm{~b}$ & $408.48 \mathrm{c}$ & $13.13 \mathrm{~b}$ \\
\hline & $59 \mathrm{~B} / 41 \mathrm{R}$ & 11.39 e & $1.02 \mathrm{~d}$ & $0.67 \mathrm{c}$ & $0.05 \mathrm{c}$ & $293.63 \mathrm{c}$ & $11.44 \mathrm{~b}$ \\
\hline & Control $^{\mathrm{y}}$ & $23.27 \mathrm{~cd}$ & $1.56 \mathrm{bc}$ & $1.17 \mathrm{bc}$ & $0.08 \mathrm{~b}$ & $466.27 \mathrm{c}$ & $14.88 \mathrm{~b}$ \\
\hline
\end{tabular}

${ }^{\mathrm{z}}$ Mean separation within columns by Duncan's multiple range test. Significant at $P=0.001$.

${ }^{\mathrm{y}}$ Control: fluorescent lamp + high-pressure sodium lamp. 
TBR' showed a significant difference between $0 \mathrm{~B}$ and the other treatments including control for the $S / R$ ratio. The $S / R$ ratio under $0 \mathrm{~B}$ was $\approx 2.6$ to 3.4 times higher than the ratio for plants grown under blue LEDcontained treatments.

$\mathrm{Fv} / \mathrm{Fm}$ varied with different blue and red LED ratios in 'Grand Rapid TBR' (Table 2). $\mathrm{Fv} / \mathrm{Fm}$ gradually decreased as the ratio of blue LEDs was reduced after 2 weeks of LED treatment. The value under $0 \mathrm{~B}$ declined to 0.75 , which was a significant decrease compared with the other treatments. At harvest, there was also a significant decrease in $\mathrm{Fv} / \mathrm{Fm}$ under $0 \mathrm{~B}$; however, significant differences between treatments having both blue and red LEDs were not observed. Control lettuce plants showed normal $\mathrm{Fv} / \mathrm{Fm}$ values $(\approx 0.815$ to 0.825 ) after both 2 and 4 weeks of LED treatment.

The blue and red LED ratio also affected the chlorophyll content in the leaves of the two leafy lettuce cultivars (Fig. 2). The SPAD value of the two lettuce cultivars grown under 0 B without blue LEDs was significantly lower compared with the other blue LED treatments and the control. For 'Sunmang',

Table 2. Chlorophyll fluorescence $(\mathrm{Fv} / \mathrm{Fm})$ of green leaf lettuce ('Grand Rapid TBR') grown under various combinations of blue and red lightemitting diodes (LEDs) at 0,2 , and 4 weeks after the onset of LED treatment $(n=3)$.

\begin{tabular}{lccc}
\hline & \multicolumn{3}{c}{ Weeks of LED treatment } \\
\cline { 2 - 4 } Light source & 0 & 2 & 4 \\
\hline $0 \mathrm{~B} / 100 \mathrm{R}$ & $0.82 \mathrm{a}^{\mathrm{z}}$ & $0.75 \mathrm{~d}$ & $0.78 \mathrm{~b}$ \\
$13 \mathrm{~B} / 87 \mathrm{R}$ & $0.82 \mathrm{a}$ & $0.79 \mathrm{c}$ & $0.82 \mathrm{a}$ \\
$26 \mathrm{~B} / 74 \mathrm{R}$ & $0.82 \mathrm{a}$ & $0.79 \mathrm{c}$ & $0.81 \mathrm{a}$ \\
$35 \mathrm{~B} / 65 \mathrm{R}$ & $0.82 \mathrm{a}$ & $0.80 \mathrm{bc}$ & $0.82 \mathrm{a}$ \\
$47 \mathrm{~B} / 53 \mathrm{R}$ & $0.82 \mathrm{a}$ & $0.82 \mathrm{ab}$ & $0.82 \mathrm{a}$ \\
$59 \mathrm{~B} / 41 \mathrm{R}$ & $0.82 \mathrm{a}$ & $0.82 \mathrm{a}$ & $0.83 \mathrm{a}$ \\
Control $^{\mathrm{y}}$ & $0.82 \mathrm{a}$ & $0.81 \mathrm{ab}$ & $0.83 \mathrm{a}$ \\
Significance & NS & $* *$ & $*$ \\
\hline
\end{tabular}

${ }^{\mathrm{z}}$ Mean separation within columns by Duncan's multiple range test. Significant at ${ }^{*} P=0.05$, $* * * P=0.001$, respectively.

${ }^{\mathrm{y}}$ Control: fluorescent lamp + high-pressure sodium lamp.

$\mathrm{NS}=$ nonsignificant . the SPAD value increased as the proportion of blue LEDs increased, showing the highest value under $47 \mathrm{~B}$. Although the change in SPAD values for 'Grand Rapid TBR' was not as clear as for 'Sunmang', treatments containing more than $26 \%$ of blue light induced high SPAD values. The SPAD values of the 'Sunmang' and 'Grand Rapid TBR' controls were similar for plants grown under $35 \mathrm{~B}$ and $26 \mathrm{~B}$, respectively.

The ratio of blue to red LEDs directly affected leaf shape for both cultivars with 2 weeks of LED treatment (Fig. 3). The leaf shape index of treatments containing blue LEDs was similar to that of the control, regardless of the blue LED ratio. In contrast, only the red LED treatment $(0 \mathrm{~B})$ induced a significantly higher leaf shape index compared with the other treatments.

Antioxidant phenolic compounds. The blue and red LED ratio significantly altered the total phenolic concentration in both cultivars (Fig. 4). In contrast to the results obtained for growth characteristics, increased blue LED ratios stimulated the accumulation of total phenolics. 'Sunmang' lettuce plants grown under $47 \mathrm{~B}$ had 1.4 and 2.4 times significantly higher total phenolic concentration compared with those grown under the control and $0 \mathrm{~B}$, respectively, at 4 weeks after the onset of LED treatment. The total phenolic concentrations under $26 \mathrm{~B}$ to $59 \mathrm{~B}$ for 'Grand Rapid TBR' were 2.2 to 2.7 times significantly higher compared with the control. The lettuce plants grown under $0 \mathrm{~B}$ and $13 \mathrm{~B}$ had similar total phenolic concentrations as the control.

Antioxidant capacity also showed a similar trend to total phenolic concentration at 4 weeks after the onset of LED treatment (Fig. 5). For 'Sunmang', as the proportion of blue LEDs increased, the production of antioxidants was promoted with the highest value being obtained under $47 \mathrm{~B}$. Although 'Grand Rapid TBR' also showed high antioxidant capacity in blue LED-rich treatments, there were no significant difference between treatments with blue LEDs above $26 \%$. When comparing the two lettuce cultivars, the red

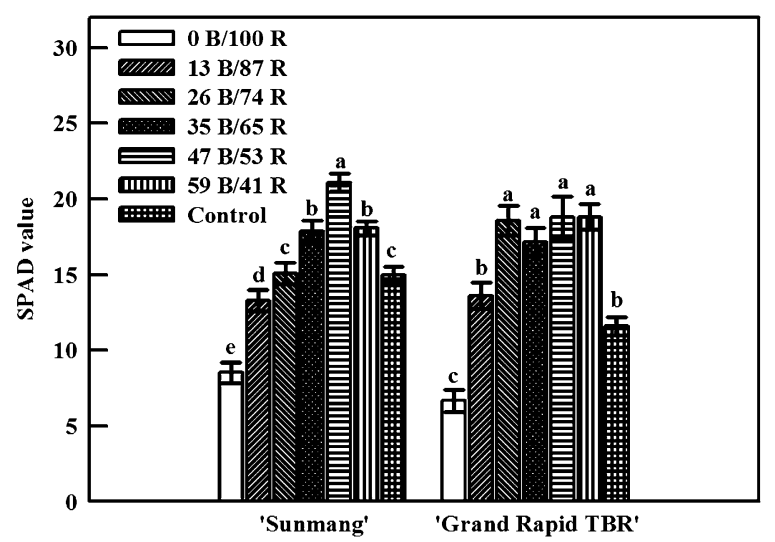

Fig. 2. SPAD value (chlorophyll content) of two lettuce cultivars grown under various combinations of blue and red light-emitting diodes (LEDs) at 4 weeks after the onset of LED treatment. Control represents fluorescent lamp and high-pressure sodium lamp. The data indicate the means $\pm \mathrm{SE}(\mathrm{n}=8)$. Significant at $P=0.001$. leaf lettuce 'Sunmang' had more antioxidants than the green leaf lettuce 'Grand Rapid TBR' under all tested light conditions.

Most changes in total flavonoid concentrations with differences in blue and red LED ratio were similar to those recorded for total phenolic concentration and antioxidant capacity in both cultivars, except under $0 \mathrm{~B}$ for 'Sunmang' (Fig. 6). Flavonoid concentration of 0 B for 'Sunmang' was similar to that of $35 \mathrm{~B}$ and $47 \mathrm{~B}$. The $59 \mathrm{~B}$ treatment induced the highest total flavonoid concentrations for 'Grand Rapid TBR'.

\section{Discussion}

In this study, varied ratios of blue to red LEDs were applied to identify the relationship of the two wavelengths in terms of lettuce growth and intracellular phenolic compounds with antioxidant properties. This aspect distinguishes the current study from previous LED-related studies, in which limited specific ratios of blue to red LEDs were applied to plants. The growth characteristic results for the two lettuce cultivars grown under various ratios of blue to red LEDs confirmed that red LED serves as a major light source that improves lettuce growth rates. As the $P P F$ of red LEDs increased, the fresh and dry weights of the shoots and roots and the leaf area increased. In addition, the $S / R$ ratio increased with increasing red LED ratio, because the growth rate of shoots was relatively higher than that of the roots. The positive effects of red light on plant growth have been reported for various crops such as perilla, chrysanthemum, tomato, poinsettia, and herbs as well as lettuce (Heo et al., 2012; Johkan et al., 2010; Lee et al., 2010; Mortensen and Strømme, 1987; Nishimura et al., 2007, 2009). Moreover, our previous study using several monochromatic LEDs indicated that red LED was the most effective at increasing the biomass of lettuce plants (Son et al., 2012). Red light is perceived by phytochrome, which is one of several photoreceptors that are known to play a major role in the growth and development of plants. Red light converts phytochrome from an inactive state to an active phytochrome with this receptor being involved in plastid development and the gene expression of chloroplasts and the nucleus (Folta and Childers, 2008). Red light also plays a crucial role in photosynthesis, because it induces $\mathrm{CO}_{2}$ absorption into the intercellular spaces of the mesophyll as a result of guard cells being stimulated and produces the energy required to open the stomata by inducing photophosphorylation in guard cells (Olsen et al., 2002; Tominaga et al., 2001). Finally, red light is effective at improving photosynthetic ability, which directly leads to the promotion of growth (Kim et al., 2005).

However, it is also of interest that one specific ratio of blue to red LEDs, i.e., the $47 \mathrm{~B} / 53 \mathrm{R}$ treatment, slightly increased lettuce weight and leaf area. These results were obtained for both lettuce cultivars, particularly the green leaf lettuce. This result 


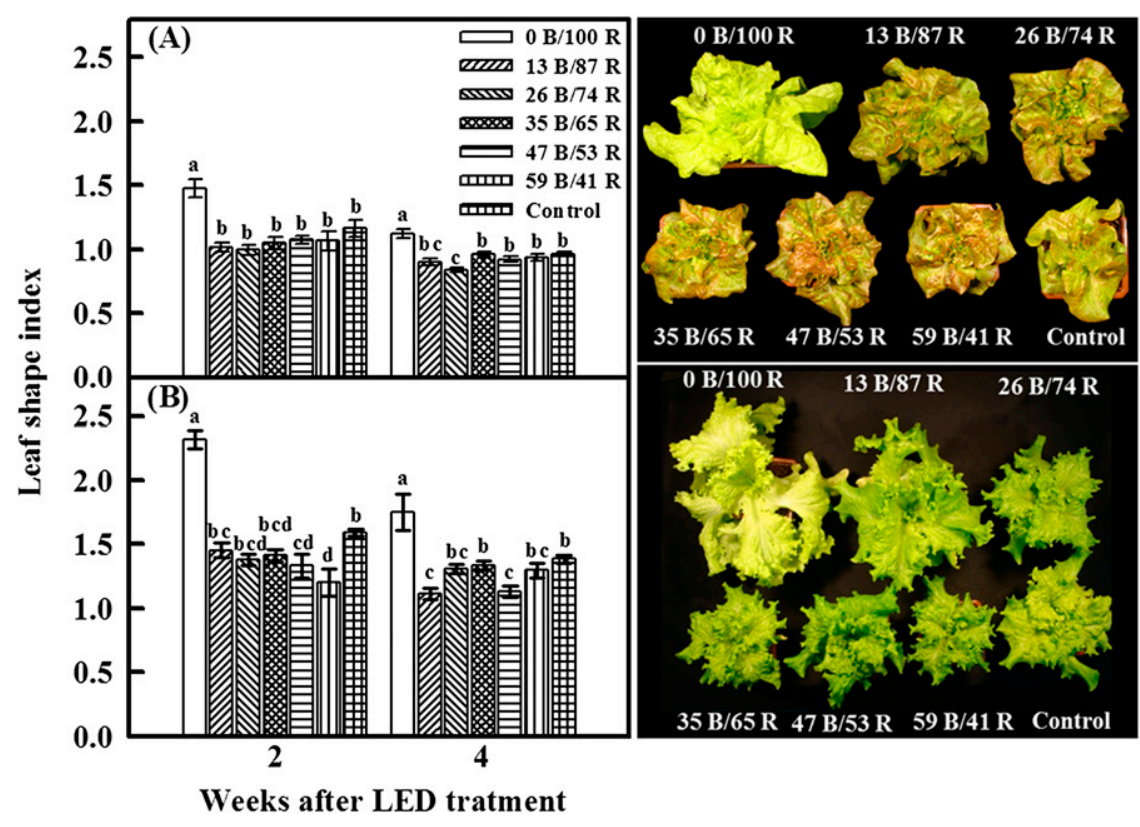

Fig. 3. Leaf shape index at 2 and 4 weeks after the onset of light-emitting diode (LED) treatment (left) and lettuce plants grown under various combinations of blue and red LEDs at 4 weeks after the onset of LED treatment (right) in both 'Sunmang' (A) and 'Grand Rapid TBR' (B). Control represents fluorescent lamp and high-pressure sodium lamp. The data indicate the means $\pm \mathrm{SE}(\mathrm{n}=8)$. Significant at $P=0.001$.

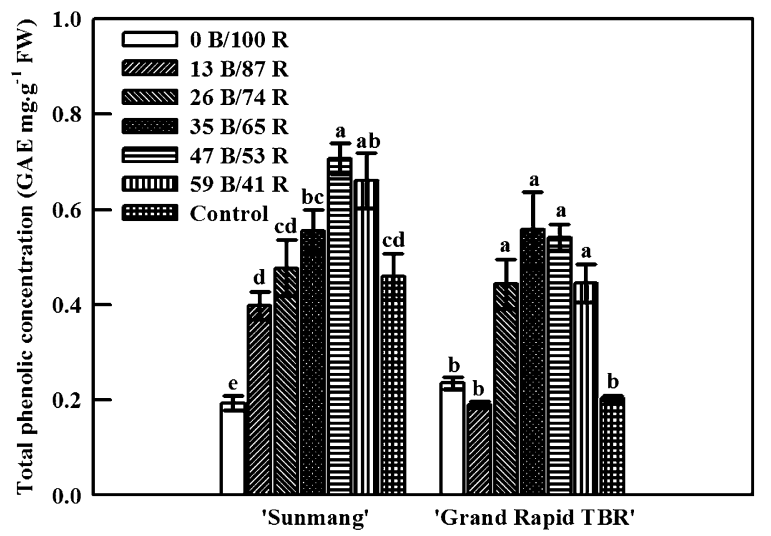

Fig. 4. Total phenolic concentrations of lettuce plants grown under various combinations of blue and red light-emitting diodes (LEDs) at 4 weeks after the onset of LED treatment. Control represents fluorescent lamp and high-pressure sodium lamp. The data indicate the means $\pm \operatorname{SE}(\mathrm{n}=4)$. Significant at $P=0.001$

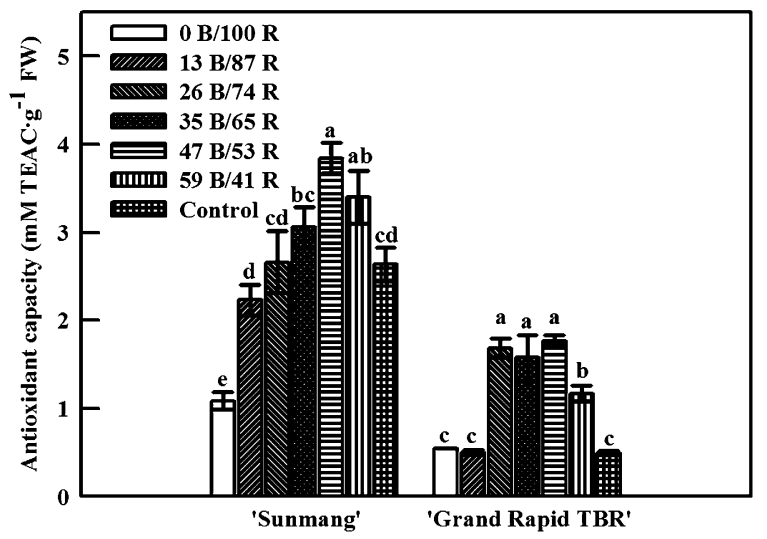

Fig. 5. Antioxidant capacity of lettuce plants grown under various combinations of blue and red lightemitting diodes (LEDs) at 4 weeks after the onset of LED treatment. Control represents fluorescent lamp and high-pressure sodium lamp. The data indicate the means \pm SE $(\mathrm{n}=4)$. Significant at $P=0.01$. probably implies that this specific blue and red LED ratio is quite effective for enhancing lettuce growth; however, further research is required to explore this finding. Stutte et al. (2009) and Yorio et al. (2001) reported that the biomass of lettuce plants grown under mixed blue and red LED lights was higher compared with plants grown under monochromatic red LEDs. When red light is used as the exclusive lighting source, the photosynthetic rate and chlorophyll fluorescence $(\mathrm{Fv} / \mathrm{Fm})$ were recorded as declining for a variety of crops (Goins et al., 1997; Hogewoning et al., 2010; Matsuda et al., 2004; Savvides et al., 2012). Healthy plants typically had 0.83 of $\mathrm{Fv} / \mathrm{Fm}$ and a low level of $\mathrm{Fv} / \mathrm{Fm}$ represents the stress level of plants from the external environment or photochemical efficiency of photosystem II (Maxwell and Johnson, 2000). The current study also showed that $100 \%$ red LED treatment $(0 \mathrm{~B})$ had lower $\mathrm{Fv} / \mathrm{Fm}$ compared with other treatments, indicating that the photosynthetic machinery may not be functioning properly, although the low value directly did not reflect reduced biomass accumulation on lettuce leaves. In comparison, net photosynthesis, stomatal conductance, $\mathrm{CO}_{2}$ fixation, and the efficiency of photosystem II was promoted by the combination of mixed blue and red LEDs, rather than monochromic red LEDs, in cucumber leaves (Hogewoning et al., 2010; Savvides et al., 2012). Typically, blue and red wavelengths are more efficiently absorbed by plant leaves compared with other visible wavelength ranges such as green and yellow, indicating that both blue and red light represent the essential wavelength ranges for plant growth and development (Lichtenthaler et al., 1980; McCree, 1972). In the current study, $0 \mathrm{~B}, 13 \mathrm{~B}$, and $26 \mathrm{~B}$ treatments for 'Sunmang' and $0 \mathrm{~B}$ and $13 \mathrm{~B}$ treatments for 'Grand Rapid TBR' induced significantly higher shoot fresh weight compared with the control and other LED treatments. The blue to red wavelength of control, which consisted of fluorescent lamps and high-pressure sodium lamps, was 61:39 (data not shown) so that the low proportion of red light may contribute to shoot fresh weight inferior to several LED treatments having a high proportion of red light. This result indicates that the use of LEDs better stimulates plant growth compared with conventional lamps in addition to saving energy.

Typically, there is a highly correlation between chlorophyll content and plant growth rate (Brougham, 1960). However, in this study, the SPAD value, which indirectly represents chlorophyll content in leaves, showed the opposite trend for the growth characteristics results, indicating chlorophyll content is not the only indicator for plant growth. Thus, it might be inferred that blue light, rather than red light, is closely associated with chlorophyll content. The primary effect of blue light on chlorophyll biosynthesis has been reported in previous studies using lettuce, cucumber, and spinach (Hogewoning et al., 2010; Lee et al., 2010; Matsuda et al., 2007). These studies reported that blue light 
had a qualitative effect, rather than a quantitative effect, on the chlorophyll biosynthesis of plants. This finding was supported by the results of the current study, whereby all LED treatments containing more than $13 \%$ blue light led to a significantly higher accumulation of chlorophyll compared with the $0 \mathrm{~B}$ treatment (i.e., without blue LEDs). In addition, our previous study comparing the various effects of monochromatic LEDs on lettuce plants demonstrated that blue LEDs improved chlorophyll content (Son et al., 2012). When comparing both lettuce cultivars, the SPAD value of 'Sunmang' gradually increased with increasing blue LED ratios; however, there was no significant difference in the chlorophyll content of 'Grand Rapid TBR' grown under treatments with more than $26 \%$ blue light. This finding indicates that different cultivars respond differently to light quality. In general, chlorophyll content is positively associated with photosynthetic ability (Buttery and Buzzell, 1977; Emerson, 1929); however, abundant chlorophyll produced by blue light did not promote plant growth in this study. This result might be because both blue and red wavelengths are required for promoting the whole photosynthetic process but the role of each wavelength somewhat differs. Indeed, it has been reported that blue light plays a major role toward generating and moving chlorophyll in plant leaves (Banaś et al., 2012; Briggs and Christie, 2002).

In the current study, clear differences were observed in the presence and absence of blue light for the leaf shape index (leaf length/leaf width), which represents the morphological characteristics of the leaf. The leaf shape index under the $0 \mathrm{~B}(100 \%$ red LED) treatment was significantly higher compared with the control and the other blue LED treatments throughout the entire growth stage. This result was consistent with previous studies, which showed that red LEDs induced lettuce leaf elongation, whereas irradiation with additional blue LEDs inhibited the expansion and elongation of leaves (Hoenecke et al., 1992; Lee et al., 2010; Stutte et al., 2009).

Recently, there has been increased research interest in the phenolic compounds contained in vegetables, including lettuce. In particular, the antioxidant activity of several thousands of phenolics is an important property, because antioxidants remove harmful reactive oxygen species that cause aging and chronic diseases in humans (Rajashekar et al., 2009). Flavonoids represent one group of phenolics that affect the color, flavor, and fragrance of plants (Hichri et al., 2011). Flavonoid content is an important factor that influences the nutritional quality of plantbased foods such as vegetables, because flavonoids have strong antioxidant activity (Ebisawa et al., 2008). The phytochemical quality of crops grown in closed-type plant production systems using LEDs as an artificial light source might be lower compared with crops grown under sunlight. However, there is limited information about how LEDs affect phytochemicals in crops with most LED-based studies primarily focusing on growth characteristics and crop yield. Thus, our study presents an interesting and useful trial, as we determined the effect of blue and red LED ratios on phenolic compounds and antioxidants in lettuce plants.

In this study, total phenolic concentration and antioxidant capacity increased with increasing blue LED ratios for two lettuce cultivars. Johkan et al. (2010) and Stutte et al. (2009) also reported that the additional irradiation of blue LEDs in combination with red LED irradiation induced the accumulation of phenolic compounds and antioxidants in lettuce plants. This phenomenon might be explained by a reduction in the growth of lettuce plants grown under LED treatments, including blue LEDs, because total phenolic concentration and antioxidant capacity are expressed through fresh weight. Indeed, there was an inverse correlation between shoot fresh weight and total phenolic concentration in the current study (Fig. 7). However, the activity of phenylalanine ammonia-lyase (PAL), which is a key enzyme in the phenylpropanoid pathway, was stimulated by the irradiation of blue LED in a previous study (Heo et al., 2012). Moreover, PAL gene expression was activated more by monochromatic blue LED

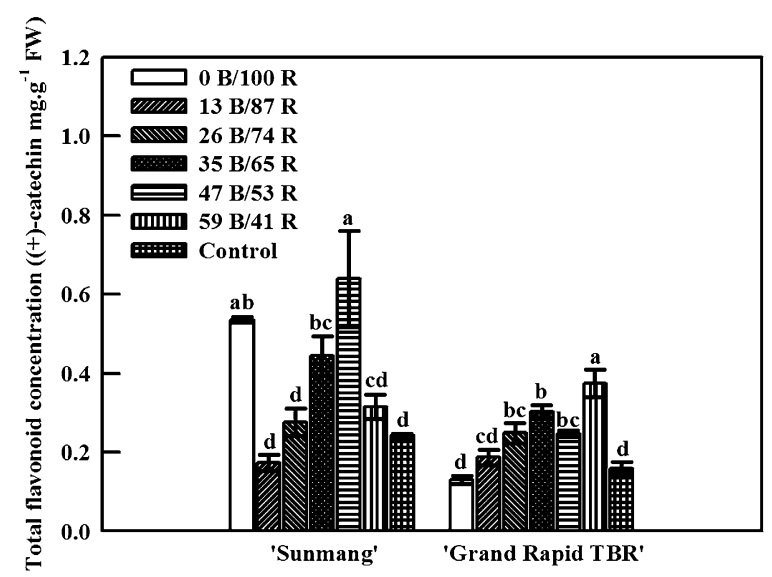

Fig. 6. Total flavonoid concentration of lettuce plants grown under various combinations of blue and red light-emitting diodes (LEDs) at 4 weeks after the onset of LED treatment. Control represents fluorescent lamp and high-pressure sodium lamp. The data indicate the means $\pm \operatorname{SE}(n=4)$. Significant at $P=0.01$

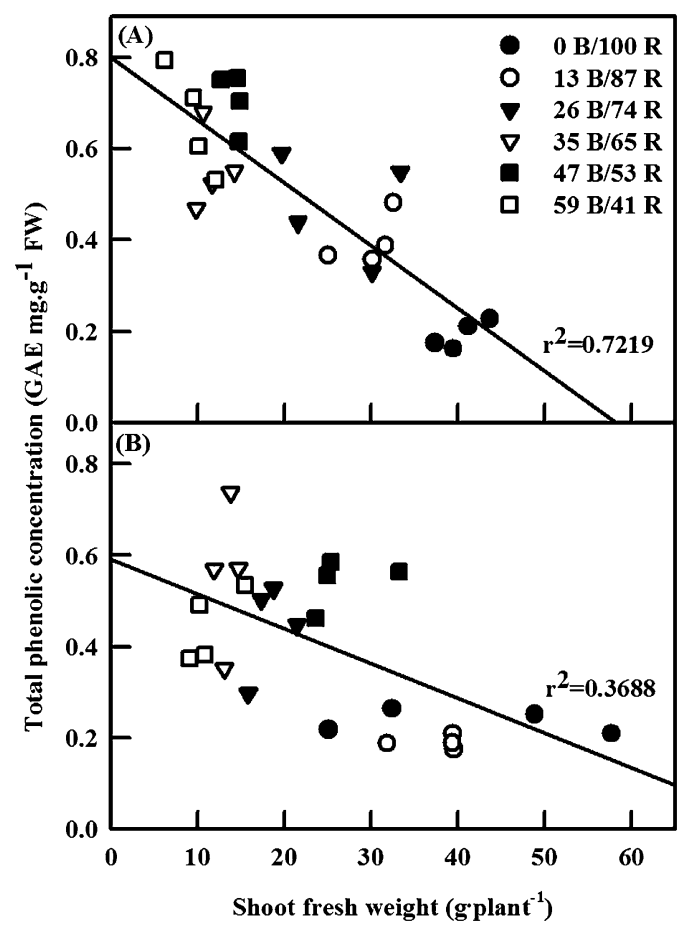

Fig. 7. Correlation of total phenolic concentration and shoot fresh weight for 'Sunmang' red leaf lettuce (A) and 'Grand Rapid TBR' green leaf lettuce (B) grown under various combinations of blue and red light-emitting diodes (LEDs) for 4 weeks after the onset of LED treatment. The data indicate the means $(n=4)$. 
than other monochromatic LEDs used on lettuce plants (Son et al., 2012). Thus, blue light might be involved in the activation of the biosynthetic pathway for secondary metabolites. In comparison, Wu et al. (2007) reported that red LEDs cause the accumulation of antioxidants in pea seedlings. Ultimately, the ability of light quality to cause the accumulation of plant secondary metabolites is probably dependent on plant species or variety (cultivar). In the current study, the two lettuce cultivars showed a difference in the accumulation of phenolic compounds and antioxidants. Although changes in the total phenolic concentration of the two lettuce cultivars grown under various blue and red LED ratios were similar, polyphenolic compounds and antioxidants were more abundant in the red leaf lettuce compared with the green leaf lettuce. This result was consistent with previous studies that compared the phytochemical content of different lettuce cultivars (Bunning et al., 2010; Liu et al., 2007). Because LED treatments caused the total phenolic concentration to change in a similar manner to that of antioxidant capacity, this study demonstrated that most phenolic compounds, including flavonoids, contribute to antioxidant capacity (Oh et al., 2009).

Finally, it may be concluded that blue and red LEDs have a positive effect on the accumulation of antioxidant phenolic compounds and lettuce growth, respectively. Red light irradiation in the absence of blue light was effective at stimulating the biomass accumulation of lettuce plants; however, this lighting alone induced abnormal leaf shape and had a negative effect on polyphenolics and antioxidant levels. Thus, based on the study results, we recommend that a mixture of blue and red LEDs is a critical lighting condition to enhance both crop quality and crop yield in closed-type plant production systems.

\section{Literature Cited}

Ainsworth, E.A. and K.M. Gillespie. 2007. Estimation of total phenolic content and other oxidation substrates in plant tissues using Folin-Ciocalteu reagent. Nat. Protoc. 2:875877.

Balasundram, N., K. Sundram, and S. Samman. 2006. Phenolic compounds in plants and agriindustrial by-products: Antioxidant activity, occurrence, and potential uses. Food Chem. 99:191-203.

Banaś, A.K., C. Aggarwal, J. Łabuz, O. Sztatelman, and H. Gabryś. 2012. Blue light signaling in chloroplast movements. J. Expt. Bot. 63:15591574.

Brandt, K., L.P. Christensen, J. Hansen-Møller, S.L. Hansen, J. Haraldsdottir, L. Jespersen, S. Purup, A. Kharazmi, V. Barkholt, H. Frøkiaer, and M. Kobaek-Larsen. 2004. Health promoting compounds in vegetables and fruits: A systematic approach for identifying plant components with impact on human health. Trends Food Sci. Technol. 15:384-393.

Briggs, W.R. and J.M. Christie. 2002. Phototropins 1 and 2: Versatile plant blue-light receptors. Trends Plant Sci. 7:204-210.

Brougham, R.K. 1960. The relationship between the critical leaf area, total chlorophyll content, and maximum growth-rate of some pasture and crop plants. Ann. Bot. (Lond.) 24:463474.

Bunning, M.L., P.A. Kendall, M.B. Stone, F.H. Stonaker, and C. Stushnoff. 2010. Effects of seasonal variation on sensory properties and total phenolic content of 5 lettuce cultivars. J. Food Sci. 75:156-161.

Buttery, B.R. and R.I. Buzzell. 1977. The relationship between chlorophyll content and rate of photosynthesis in soybeans. Can. J. Plant Sci. 57:1-5.

Carvalho, R.F., M. Takaki, and R.A. Azevedo. 2011. Plant pigments: The many faces of light perception. Acta Physiol. Plant. 33:241-248.

Dewanto, V., X. Wu, K.K. Adom, and R.H. Liu. 2002. Thermal processing enhances the nutritional value of tomatoes by increasing total antioxidant activity. J. Agr. Food Chem. 50: 3010-3014.

Ebisawa, M., K. Shoji, M. Kato, K. Shimomura, F. Goto, and T. Yoshihara. 2008. Supplementary ultraviolet radiation $\mathrm{B}$ together with blue light at night increased quercetin content and flavonol synthase gene expression in leaf lettuce (Lactuca sativa L.). Envrion. Control Biol. 46:1-11.

Emerson, R. 1929. The relation between maximum rate of photosynthesis and concentration of chlorophyll. J. Gen. Physiol. 12:609-622.

Folta, K.M. and K.S. Childers. 2008. Light as a growth regulator: Controlling plant biology with narrow-bandwidth solid-state lighting systems. HortScience 43:1957-1964.

Goins, G.D., N.C. Yorio, M.M. Sanwo, and C.S Brown. 1997. Photomorphogenesis, photosynthesis, and seed yield of wheat plants grown under red light-emitting diodes (LEDs) with and without supplemental blue lighting. J. Expt. Bot. 48:1407-1413.

Heo, J.W., D.H. Kang, H.S. Bang, S.G. Hong, C. Chun, and K.K. Kang. 2012. Early growth, pigmentation, protein content, and phenylalanine ammonia-lyase activity of red curled lettuces grown under different lighting conditions. Kor. J. Hort. Sci. Technol. 30:6-12.

Hichri, I., F. Barrieu, J. Bogs, C. Kappel, S. Delrot, and V. Lauvergeat. 2011. Recent advances in the transcriptional regulation of the flavonoid biosynthetic pathway. J. Expt. Bot. 62:24652483.

Hoenecke, M.E., R.J. Bula, and T.W. Tibbitts. 1992. Importance of 'Blue' photon levels for lettuce seedlings grown under red-light-emitting diodes. HortScience 27:427-430.

Hogewoning, S.W., G. Trouwborst, H. Maljaars, H. Poorter, W. van Ieperen, and J. Harbinson. 2010. Blue light dose-responses of leaf photosynthesis, morphology, and chemical composition of Cucumis sativus grown under different combinations of red and blue light. J. Expt. Bot. 61:3107-3117.

Hooper, L. and A. Cassidy. 2006. A review of the health care potential of bioactive compounds. J. Sci. Food Agr. 86:1805-1813.

Hopkins, W.G. and N.P.A. Huner. 2004. Introduction to plant physiology. 3rd Ed. John Wiley and Sons, Hoboken, NJ.

Jiao, Y., O.S. Lau, and X.W. Deng. 2007. Lightregulated transcriptional networks in higher plants. Nat. Rev. Genet. 8:217-230.

Johkan, M., K. Shoji, F. Goto, S. Hashida, and T. Yoshihara. 2010. Blue light-emitting diode light irradiation of seedlings improves seedling quality and growth after transplanting in red leaf lettuce. HortScience 45:1809-1814.

Kim, H.H., R. Wheeler, J. Sager, and J. Norikane. 2005. Photosynthesis of lettuce exposed to different short term light qualities. Environ. Control Biol. 43:113-119.

Lee, J.G., S.S. Oh, S.H. Cha, Y.A. Jang, S.Y. Kim, Y.C. Um, and S.R. Cheong. 2010. Effects of $\mathrm{red} / \mathrm{blue}$ light ratio and short-term light quality conversion on growth and anthocyanin contents of baby leaf lettuce. J. Bio-Environ. Control 19:351-359.

Lichtenthaler, H.K., C. Buschmann, and U. Rahmsdorf. 1980. The importance of blue light for the development of sun-type chloroplasts. In: Senger, H. (ed.). The blue light syndrome. Springer-Verlag, Berlin, Germany.

Liu, X., S. Ardo, M. Bunning, J. Parry, K. Zhou, C. Stushnoff, F. Stoniker, L. Yu, and P. Kendall. 2007. Total phenolic content and DPPH radical scavenging activity of lettuce (Lactuca sativa L.) grown in Colorado. Swiss Soc. Food Sci. Technol. 40:552-557.

Matsuda, R., K. Ohashi-kaneko, K. Fujiwara, E. Goto, and K. Kurata. 2004. Photosynthetic characteristics of rice leaves grown under red light with or without supplemental blue light. Plant Cell Physiol. 45:1870-1874.

Matsuda, R., K. Ohashi-kaneko, K. Fujiwara, and K. Kurata. 2007. Analysis of the relationship between blue-light photon flux density and the photosynthetic properties of spinach (Spinacia oleracea L.) leaves with regard to the acclimation of photosynthesis to growth irradiance. Soil Sci. Plant Nutr. 53:459-465.

Maxwell, K. and G.N. Johnson. 2000. Chlorophyll fluorescence-A practical guide. J. Expt. Bot. 51:659-668.

McCree, K.J. 1972. Action spectrum, absorptance and quantum yield of photosynthesis in crop plants. Agr. Meteorol. 9:191-216.

Miller, N.J. and C.A. Rice-Evans. 1996. Spectrophotometric determination of antioxidant activity. Redox Rpt. 2:161-171.

Morrow, R.C. 2008. LED lighting in horticulture. HortScience 43:1947-1950.

Mortensen, L.M. and E. Strømme. 1987. Effects of light quality on some greenhouse crops. Sci. Hort. 33:27-36.

Nishimura, T., K. Ohyama, E. Goto, and N. Iangaki. 2009. Concentration of perillaldehyde, limonene, and anthocyanin of Perilla plants as affected by light quality under controlled environments. Sci. Hort. 122:134-137.

Nishimura, T., S.M.A. Zobayed, T. Kozai, and E. Goto. 2007. Medicinally important secondary metabolites and growth of Hypericum perforatum L. plants as affected by light quality and intensity. Envrion. Control Biol. 45:113-120.

Oh, M.-M., E.E. Carey, and C.B. Rajashekar. 2009. Environmental stresses induce health-promoting phytochemicals in lettuce. Plant Physiol. Biochem. 47:578-583.

Olsen, R.L., R.B. Pratt, P. Gump, A. Kemper, and G. Tallman. 2002. Red light activates a chloroplast-dependent ion uptake mechanism for stomatal opening under reduced $\mathrm{CO}_{2}$ concentrations in Vicia spp. New Phytol. 153:497508.

Pennington, J.A.T. and R.A. Fisher. 2009. Classification of fruits and vegetables. J. Food Compost. Anal. 22:23-31.

Pennycooke, J.C., S. Cox, and C. Stushnoff. 2005. Relationship of cold acclimation, total phenolic content and antioxidant capacity with chilling tolerance in petunia (Petunia $\times$ hybrida). Environ. Exp. Bot. 53:225-232.

Rajashekar, C.B., E.E. Carey, X. Zhao, and M.-M. Oh. 2009. Health-promoting phytochemicals in fruits and vegetables: Impact of abiotic stresses and crop production practices. Functional Plant Sci. Biotechnol. 3:30-38. 
Savvides, A., D. Fanourakis, and W. van Ieperen. 2012. Co-ordination of hydraulic and stomatal conductances across light qualities in cucumber leaves. J. Expt. Bot. 63:1135-1143.

Son, K.-H., J.-H. Park, D. Kim, and M.-M. Oh. 2012. Leaf shape, growth, and phytochemicals in two leaf lettuce cultivars grown under monochromatic light-emitting diodes. Kor. J. Hort. Sci. Technol. 30:664-672.

Stutte, G.W., S. Edney, and T. Skerritt. 2009. Photoregulation of bioprotectant content of red leaf lettuce with light-emitting diodes. HortScience 44:79-82.
Tominaga, M., T. Kinoshita, and K. Shimazaki. 2001. Guard-cell chloroplasts provide ATP required for $\mathrm{H}^{+}$pumping in the plasma membrane and stomatal opening. Plant Cell Physiol. 42:795-802.

Wang, H., M. Gu, J. Cui, K. Shi, T. Zhou, and J. $\mathrm{Yu}$. 2009. Effects of light quality on $\mathrm{CO}_{2}$ assimilation, chlorophyll-fluorescence quenching, expression of Calvin cycle genes and carbohydrate accumulation in Cucumis sativus. J. Photochem. Photobiol. B 96:30-37.

Wu, M.C., C.Y. Hou, C.M. Jiang, Y.T. Wang, C.Y Wang, H.H. Chen, and H.M. Chang. 2007. A novel approach of LED light radiation improves the antioxidant activity of pea seedlings. Food Chem. 101:1753-1758

Yeh, N. and J.-P. Chung. 2009. High-brightness LEDs-energy efficient lighting sources and their potential in indoor plant cultivation. Renew. Sustain. Energy Rev. 13:2175-2180.

Yorio, N.C., G.D. Goins, J.C. Sager, R.M Wheeler, and J.C. Sager. 2001. Improving spinach, radish, and lettuce growth under red light-emitting diodes (LEDs) with blue light supplementation. HortScience 36:380383. 